\title{
POLYMER-MODIFIED CONCRETE: REVIEW
}

\author{
Shivani R. Bothra' ${ }^{1}$, Yuvraj M. Ghugal ${ }^{2}$ \\ ${ }^{1}$ Student M.E. Structural Engineering, Department of Applied Mechanics, Govt. college of engineering Karad 415124, \\ Dist: satara, (M.S) \\ ${ }^{2}$ Professor \& head of Applied Mechanics Dept. Govt. college of engineering Karad, 415124, Dist: satara, (M.S)
}

\begin{abstract}
Concrete plays important role in the construction industry but it has some drawbacks. To overcome this drawbacks the search for durable and sustainable construction materials is the need of time. This leads to the developments of concrete composites in combination of various compounds to be used in many applications in world of cement concrete. A better knowledge of materials behaviour, especially in the field of admixtures, and a better understanding of curing processes allowed the development of highly performing mineral or modified mineral concretes, mortars and grouts. The world of concrete with fibres, as well as the world of concrete- with polymer has been undergoing major researches to enhance the properties of traditional concrete. Both worlds recognize, strive for and accept each other's contribution to the synergic effects that are realized by the combination of classical building materials and polymers. This paper briefly review the use concrete composites in combination with polymer, where polymers are in the form of a polymerised matrix comingled with the hydrated cement paste. The micro-structure and properties of composite polymer modified concrete are described and some current possible applications are mentioned. It is observed that using fibers in combination with polymer show further enhancement.Various methodology, emerging trends as well as variations in curing techniques for polymer modified concrete are observed. Also the modern strengthening techniques used for improving the earthquake behaviour of structures, by aid of fibre reinforced polymers (FRP) are discussed for the use of rehabilitation of existing structures.Several recently published articles and technical papers dealing polymer modified concrete are critically reviewed.
\end{abstract}

Keywords: Polymer, SBR latex, Acrylic polymer, Steel fiber.

\section{INTRODUCTION}

The concrete is a popular building material in the world for past 170 years and more. Though worldwide used concrete has biggest disadvantages such as delay in hardening, low tensile strength, large drying shrinkage and low chemical resistance. To overcome this disadvantages attempts is made by modifying cement concrete with polymer additives, such as thermoplastics, thermo sets like epoxy resins which hardens, elastomers or rubbers, naturals polymers cellulose, lignin and proteins. Polymers are preferred in the cement composites due to high performance, multi-functionality and sustainability compared to conventional cement concrete. Polymer modified concrete have monolithic co matrix in which the organic polymer matrix and cement gel matrix homogenized. Several types of polymer such as latex, redispersible polymer powder, water soluble powder, liquid resins and monomers modified concrete are used. Although polymers and monomers are used in cement composites it is very important that cement hydration and polymer phase formation proceed well to yield a monolithic matrix phase with network structure, in which the hydrated cement phase and polymer phase interpenetrate; also the aggregate are bounds by such co-matrix phase resulting in the superior quality of polymer modified concrete compound.

Styrene butadiene rubber latex is type of high polymer dispersion emulsion widely used as a polymer. SBR composed of butadiene, styrene, water and it can be successfully bounded to many materials. It is used to replaced cement binders to improve tensile, flexural and compressive strength of concrete. SBR is a wide thick liquid in appearance with high viscosity $52.7 \%$ water content. [1] However polymers in combination with steel fiber reinforcement are proving boon in terms of strength, cohesiveness, excellent durability, resistance to acid alkalis[2]. Hence this material found to be used in corrosive environment as corrosion resistance material[3]. Concrete polymers composite are environment conscious and confirm to concerns saving of that natural resources, the longetivity of infrastructure and environmental protection.

\section{HISTORY OF POLYMERS IN CONCRETE}

Polymers have been used in construction as long ago as the fourth millennium B.C., when the clay brick walls of Babylonia were built using the natural polymer asphalt in the mortar. The temple of Ur-Nina (King of Lagash), in the city of Kish, had masonry foundations built with mortar made from 25 to $35 \%$ bitumen (a natural polymer), loam, and chopped straw or reeds. The walls of Jericho were built using bituminous earth in about 2500-2100 B.C. Other historic applications of bituminous mortars in construction have been identified in the ancient Indus Valley cities of Mohenjo-Daro and Harappa around 3000 B.C., and near the Tigris River in 1300 B.C, Many natural polymers have been used in ancient mortar, including albumen, blood, rice paste, and others (Chandra and Ohama 1994). The earliest indication of the use of polymers in PCC was apparently in 1909, in the United States, when a patent for such use was 
granted to L. H. Backland; and in 1922, in France, when a patent was granted to M. E. Varegyas. In Britain, polymers in concrete advanced in 1923 with L. Cresson's patent for rubber-modified road surfacing material; in 1924 with V. Lefebure's development of natural rubber latex cement; and in 1925 by S. H. Kirkpatrik's innovation on that product (Ohama 1978; Chandra and Ohama 1994). Synthetic polymers were invented in the 1940s in response to the wartime decline in the availability of natural rubber and the increased demand of the war effort. Incorporation of synthetic polymers in portland cement mortars and concrete started in the 1950s (Dikeou 1978; Chandra and Ohama 1994).

\section{MICROSTRUCTURE OF POLYMER}

Concrete polymer composites are generally classified as Polymer impregnated concrete (PIC) is a hydrated Portland cement concrete which has been impregnated with monomer and subsequently polymerized in situ, Polymer concrete (PC) is a composite material formed by polymerizing a monomer and aggregate mixture. The polymerized monomer acts as the binder for the aggregate, Polymer modified concrete (PMC) and also called polymer Portland cement concrete (PPCC) is a premixed material in which either a monomer

When polymer firstly mixed with fresh concrete, polymer particles suspended in the latex are ideally dispersed throughout cement paste. Cement hydration starts, saturating the solution with $\mathrm{CH}$, and generating ettringite and $\mathrm{CH}$ crystals in the zone adjacent to aggregates and probably calcium silicate layer on the aggregate forms. Polymer particles deposit on the gel products and on the unhydrated clinker particles. With the consumption of water by the hydration process, and the growth of hydration products, the polymer particles gradually concentrate in the capillary pores, forming a close packed layer on the gel product surfaces, on the unhydrated cement grains and on the developing silicate layer over the aggregates. The accumulating polymer particles eventually fill many of the capillary pores and coat the inner surfaces of those they don't completely fill. When water is further withdrawn by hydration or drying, the close-packed polymer particles on the gel products and in the voids coalesce into continuous films or membranes, forming a co matrix intermingled with the hydrated cement paste and binding the hydrates to each other to the aggregates. Some polymers participate in chemical reactions with the cement hydration products to the detriment of the composite.[4]

\section{APPLICATIONS}

PMC are primarily used as overlays on roadway and bridges, both as new construction and as repairs of existing deteriorated structures[5]. PMC is being used in floorings, water tanks, swimming pools, septic tanks, silos, drains, pipes and ship decks [6]. Relatively new application which proved to be very promising are its use in combination with fiber reinforcing[7][8][9]. And its use as pneumatically applied material in shotcrete[10]. As a repairing material
PMC is also used for concrete and stone repair material, as cement adhesives, prefabricated building components like flag stone, tubes, panels, porous and eco concrete, machine base elements and chemical resistance material, industrial floor and liquid applied and water profing materials[11]. Possible future applications includes roller compacted concrete (RCC) for air strips, roadways, parking lots and ductile concrete foundation, shear wall connection. Its use is also predicted for marine and offshore structures.

\section{EXAMPLES FROM THE LITERATURE}

\subsection{Review Paper 1}

Y.M.Ghugal(1994) elaborated the experimental study with polymer modified cement mortars. The variables considered were polymer content, age of curing and type of curing. The effects of polymer admixture on compressive, split tensile, flexural strength and workability were studied. The dosage of polymer were varied from $0-25 \%$. Also, the effects of wet and dry curing were observed at various ages of curing. results were compared with controlled mortar without polymer. The substantial increase in flexural, split tensile and compressive strength at the later age was observed for the air cured specimen in comparison to water cured specimens. The optimum polymer content was found to be $20 \%$. The higher early strength and adhesion to old building materials enables the structures to be restored in the shortest possible time. In concrete buildings the loose concrete is removed and the resulting voids are filled with high early strength materials . the polymer $r$ modified mortar and concretes could be employed in various techniques of repair ,restoration and strengthening of concrete and masonary structures depending upon the type and extent of damage caused by earthquake.

Use of polymer in cement mortar make the mortar more workable with low water cement ratio improving strength. Air curing is preferd to increase higher rate strength at later ages. Materials due to its significant improvement in mechanical properties and durability were efficiently used as rehabilitation of distressed, damaged and deteriating concrete and masonary structures to be restored and strengthend in possible shortest time.

\subsection{Review Paper 2}

R. Wang (2009) paper state the comparative behavior of micro and macro mechanical properties of SBR with cementitious materials. In this study it is observed that the mechanical properties deals with SBR latex modified cement pastes, identified by means of the nanoindentation (NI) while macro mechanical properties deals with SBR latex modified mortars identified by the standard test methods. During experimentation w/c ratio in both cases is kept constant as $0.4 \%$ by weight of cement while the $\mathrm{P} / \mathrm{C}$ ratio is varied from $0-20 \%$. For this purpose the results compared in terms of average values of hardness, indentation modulus of cement paste identified by NI and the compressive, flexural strength of mortar was identified by dynamic elastic modulus of mortar. A linier co relation is observed between micro mechanical properties and 
macroscopic properties of cementitious composites. The encountered linear relation between the microscopic and macroscopic strength properties highlights the finer scale origin of the performance of SBR latex modified mortar. It is also observed that SBR latex modification mainly affects the elastic properties of cementitious material identified by NI and dynamic elastic modulus for different length scale that is mortar and cement pastes respectively. Addition of aggregate have impact as of mortar.[12][13]. According to observation I supposed to say that the same result followed for concrete composites. As the polymer to cement ratio increases up to $10 \%$ the beneficial effects of $\mathrm{P} / \mathrm{C}$ ratio was in terms of toughness as well as continuous reduction in the ratio between the compressive and flexural strength is observed. A increment in porosity was observe due to addition of $10 \%$ SBR latex had a large impact on the flexural strength mainly controlling flexural strength of mortar. A P/C ratio of $8-10 \%$ was found as the optimum SBR latex content in practical application.

\subsection{Review Paper 3}

V.M.Sautaraja et al (2013) present a study to analyse the properties of concrete that can be further improved by addition of SBR polymer along with steel fiber. This paper states that gain in strength due to combined addition of steel fiber and polymer SBR latex in normal concrete leads to increase strength, durability, toughness, resistance to cracking and crack propogation. Also the effect of curing condition on th strength gain properties of composite were observed. $\mathrm{P} / \mathrm{C}$ ratio keeping constant steel fiber varied with increment of $0.75 \%$ and $1.5 \%$ bt wt. of cement:a tremendous increase in compressive strength and post cracking ductility is imported to concrete. Test results were observed in terms of flexure and compressive strengths, the increment in flexureal and compressive strength were more effective in dry curing while in wet curing the strength decreases. Hence it is suppose to be concluded that wet curing is detrimental to the strength of concrete. Decrease in workability due to addition of steel fibres is compensated in polymeric additives in dry curing condition.

\subsection{Review Paper 4}

Sivakumar.M.V.N(2011) study states the comparative effect of different polymers on structural properties of concrete. In this study a mechanical and flexural properties of polymer modified concrete were observed. Two different types of the polymers latex-styrene butadiene and styrene acrylic were used for varying dosages (0-20\%) to modify concrete composites individually in each case. A graphical comparison of results were carried out for $7^{\text {th }}$ day as well as $28^{\text {th }}$ day. A significance of this experiment was wet curing process was carried upto testing date. It was also observe that the dosages of polymer in both the cases is optimal for $15 \%$ polymer. While justifying potence of each polymer it was interpreted that Acrylic styrene was proved superior over latex polymer because of its fine particle size and relatively less viscosity.

\subsection{Review Paper 5}

R. Radhakrishnan(2012) this study explained the application of polymer for repairing existing concrete structures for repairing existing concrete structures. In order to repair structures for enhancing the service life ,number of methods and materials available, but the degree of success of any repair in concerte depends mainly on the correct choice and the method of application of repair material. Repair techniques mainly depends on resistance to water penetration and tensile cracking of structure. To study the effect of SBR latex with cementitious material. A mix proportion of mortar 1:3 with added SBR at 20\% by weight of cement were made. A comparative study was carried out carried between added SBR specimen and control specimen without SBR in terms of compressive strength and split tensile strength for repaired cylinder were tested. Also sorptivity test was carried along with the influence of thermal cycling on repaired concrete. From the study result it is interpreted that SBR modified cement mortar possess very good water penetration as well SBR as bonding agent possess good tensile strength compared to cement slurry . A SBR as a modifier and as a bonding agent to cement mortar satisfies the requirement by the standard of ASTM. SBR modifier upholds better performance after thermal cycling hence proved boon for structure in tropical climate.

\subsection{Review Paper 6}

Z.A. Siddhiqi et.al.(2013) in his research states the effects of addition of polymer SBR latex in concrete in terms of compressive strength and water absorption. And observation is made that SBR latex improves the internal structure of latex modified concrete resulting in considerable reduction in the water absorption value at 28 days. A comparison was observed between SBR modified concrete in controlled concrete. From results it is concluded that enhancement in compressive strength and reduction in water absorption was observed on 28 days while on $7^{\text {th }}$ day the early compressive strength shows negative effects and at early age water absorption was adverse. Specimens are varied from 5\%, $10 \%, 20 \%$ of polymer dosages. Modification of concrete by polymer leads to increase workability in comparison to control concrete max increase in compressive strength was observed to $72 \%$ as well reduction in water absorption was observed at $30 \%$. Its concluded that thin polymeric film restored the water by hydration process and helps in reduction in water absorption.

\subsection{Review Paper 7}

Abdulkader Ismail A.AL.Hadithi et.al.(2009) explained the mechanical properties of steel fiber concrete in combination of acrylic polymers. In this study fiber percentage are varied $0.5 \%$ by weight of cement upto $1.5 \%$ as well as acrylic polymer content are varied as $3 \%, 7 \%$ and $10 \%$ by weight of cement. Significant curing of specimens carried as total water immersed curing by Folic method.[13] Result observed showed an improvement in all properties of control concrete when steel fibers were added. While addition of acrylic polymers along with steel fiber showed a 
greater influence than steel fiber reinforced concrete. There was (14.2\%-29.2\%) increment in compressive strength of steel fiber reinforced concrete, while it was found (44.8$86.64 \%$ ) increment in PMSFRC. Splitting tensile strength the increase upto(50-91\%) was observed for steel fibres concrete which goes on increasing upto (102.4-124.7\%) in case of PMSFRC. Similar increment was observed in flexural strength as (24.2-48.3\%) for SFRC and (62-78\%) for PMSFRC.7\% of P/C was found to be optimal with $1 \%$ variation in the volume fraction.

\section{CONCLUSION}

There is a large variation in use of polymer in construction industry. the synergic action of polymers and cement mortars, concrete offer great improvement for wide range of new and innovative applications increasing tensile strength of composites, less water curing, resistance to cracking, impermeability high impact, good quality of sorptivity has proved polymer as best modifiers for the composites. The use of polymer should be well considered to guarantee better performance and improve sustainability.

Polymers are not only special construction materials that replace classical minerals or organic building materials but also allow new development of new and durable construction as well as new restoration and retrofitting techniques.

\section{REFERENCES}

[1] Ohama Y., Concrete Admixtures Handbook (Properties, Science and Technology), Noyes publication, Park ridge, New Jersey,U.S.A.,1924.

[2] Rong,li et al.,Polymers in concrete,Proc .First Asia symposium

EASPIC),Chuchion,Koria,1994,pp.293-300.

[3] Fowler, D. W. ,Polymers in concrete Handbook of structural concrete, Mc- Graw-Hill publication, New York, 1983.

[4] Joshua B. kordan, Polymer Modified ConcreteReview, Journal of materials in civil engineering, vol.no.9,1997.pp.85-92.

[5] Darwin ,D,et.al,Causes Evaluation And Repair Cracks In Concrete Structures,American Concrete Journal,vol.no. 9,1984, pp.224.

[6] Ohama, Y.,Development of Concrete-Polymer Matrials in Japan, Proc.polymers in concrete, American Concrete Journal,1978,pp.121-137.

[7] Gerwick, Ben C.Jr., Application Of Polymers To Concrete Sea Structure, Proc.Polymers In Concrete, American Concrete Journal,1978,pp.37-43.

[8] Soraushian, P. ,Tilli, A., Y.Ohama, M., and Tilsen,B.L., Durability Characteristics of PolymerModified Glass Fiber Reinforced Concrete, American Concrete Material Journal,90,1993,pp.40-49.

[9] Zayat ,k., and Bayasi, Z., Effect Of The Latex On Mechanical Properties Of Carbon Fiber Reinforced Cement, American Concrete Material Journal ,vol.no.93, 1996, pp.178-181
[10] Schorn, H. ,Epoxy Modified Shotcrete Polymer Concrete Uses ,Materials And Properties, American Concrete Material Journal, vol.no89,1985, pp.249260.

[11] D. Van Gemant,L.Czarneki,P.Lukouski and E Knapen., Cement concrete and concrete- polymer composites :Two merging worlds, A report from $11^{\text {th }}$ ICPIC congress in Berlin ,2004,pp.1-6.

[12] Benard ,O.,Ulm,F-J and Lemarchand,E., A Multiscale Micromechanics Hydration Module For The Early Age Elastic Properties Of Cement Based Materials, cement concrete journal,33,2003.pp.12931309.

[13] Pichler, ch., Lackner,R. and Mang, H.A., A Multiscale Microemechanics Model For The Autogenous Shrinkage Deformation Of Early Age Cement Based Materials, Enggn. Fracture Mechanics,34,2006,pp.1-25.

[14] Folic Radomir J. and Radanjanin,VlasmirS.,Experimental Research Of Polymer Modified Concrete,American Concrete Institute Material Journal ,95-4,1998,pp.463-469.

[15] Y.M. Ghugal, Polymer modified mortar: A material for strengthening of earthquake damaged structures, Proc. Tenth symposium on earthquake enginnering, Roorkee, 1994,pp.16-18.

[16] R. Wang,R. Lackner and P.M.Wang,Effect Of Styrene Butadiene Rubber Latex On Mechanical Properties Of Cementitious Materials Highlighted By Means Of Nanoindentation,International Journal For Experimental Mechanics, 2009,pp.117-126.

[17] V.M.Southarajan, Deependrasingh, Shreyansh Parakh,S.Thirumurugan and A.Shivkumar, Strain Hardening Properties Of Steel Fibres Reinforced Latex Concrete Composites, International Journal Of Engineering And Technology,5,2013,pp.1355-1367.

[18] Sivakumar.M.V.N.,Effect of Polymer Modification On Mechanical And Structural Properties Of Concrete-An Experimental Investigation, Interational Journal of Civil And Structural Enggneering,4,2011,pp.730-740.

[19] R.Radhakrishnan, Syam prakash. V,C.K.Prasad Verma Thampan, Performance Of Styrene Butadiene Rubber As A Concrete Repairs Material Intropical Climate, International Journal of Advancement In Research And Technology,6,2012,pp1-5

[20] Z. A. Siddiqi, R. Hameed, M. Saleem, Q. S. Khan and Jawad A. Qazi, Determination of compressive strength and water absorption of styrene butadiene rubber latex modified concrete, Pakistan journal of science, 1,2013,pp.124-128.

[21] Abdulkader Ismail A.Al-Hadithi and Ghassan S. Jameel Al-Kubaysi, Improving The Mechanical Properties Of Steel Fiber Concrete Using Acrylic Polymer ,The Iraqi Journal Of Mechanical And Material Engineering,(D),2013,pp.1-15. 